\begin{tabular}{|c|c|c|}
\hline \multirow{3}{*}{$\begin{array}{r}\text { Case Reports in } \\
\text { Gastroenterology }\end{array}$} & \multirow{2}{*}{\multicolumn{2}{|c|}{ Case Rep Gastroenterol 2015;9:29-35 }} \\
\hline & & \\
\hline & $\begin{array}{l}\text { DOI: 10.1159/000375117 } \\
\text { Publisned online: January } 24,2015\end{array}$ & $\begin{array}{l}\text { ( } 2015 \text { S. Karger AG, Basel } \\
\text { 1662-0631/15/0091-0029 } \$ 39.50 / 0 \\
\text { www.karger.com/crg }\end{array}$ \\
\hline & \multicolumn{2}{|c|}{$\begin{array}{l}\text { This is an Open Access article licensed under the terms of the Creative Common } \\
\text { Attribution-NonCommercial } 3.0 \text { Unported license (CC BY-NC) (www.karger.com/OA } \\
\text { license), applicable to the online version of the article only. Distribution permitted for non } \\
\text { commercial purposes only. }\end{array}$} \\
\hline
\end{tabular}

\title{
Peritoneal Recurrence of Initially Controlled Hepatocellular Carcinoma after Living Donor Liver Transplantation
}

\author{
Nariman Sadykov ${ }^{a, b} \quad$ Akihiko Soyama $^{a} \quad$ Masaaki Hidaka $^{a}$ \\ Ayaka Kinoshita $^{a}$ Mitsuhisa Takatsuki $^{a}$ Tomohiko Adachi ${ }^{a}$ \\ Amane Kitasato $^{a}$ Fumihiko Fujita $^{a}$ Tamotsu Kuroki $^{\mathrm{a}}$ Susumu Eguchi ${ }^{\mathrm{a}}$ \\ aDepartment of Surgery, Nagasaki University Graduate School of Biomedical Sciences, \\ Nagasaki, Japan; ${ }^{b}$ Department of HPB Surgery, Syzganov's National Scientific Center of \\ Surgery, Almaty, Kazakhstan
}

\section{Key Words}

Hepatocellular carcinoma · Liver transplantation · Peritoneal recurrence

\begin{abstract}
It is well known that the presence of end-stage liver disease increases the risk of developing hepatocellular carcinoma (HCC). Liver transplantation (LT) for patients within the Milan criteria has become a standard treatment for HCC in most developed centers worldwide. However, a major cause of death in cirrhotic patients with HCC after transplantation is tumor recurrence, including peritoneal recurrences, which develops rarely but presents a significant problem with regard to their management. Our experience includes two cases with HCC within the Milan criteria of peritoneal recurrences after living donor LT. Both patients had interventions for HCC in their medical history before $\mathrm{LT}$, and we propose that these might have been a possible cause of the HCC peritoneal recurrence.

(c) 2015 S. Karger AG, Basel
\end{abstract}

\section{Introduction}

Several lines of evidence indicate that the presence of end-stage liver disease increases the risk of developing hepatocellular carcinoma (HCC). The prevalence of cirrhosis in patients with HCC is about $80-90 \%$ [1]. Since HCC is the third leading cause of cancer-related

KARGER 125/s $\quad \begin{aligned} & \text { Susumu Eguchi, MD, PhD } \\ & \text { Department of Surgery } \\ & \text { Nagasaki University Graduate School of Biomedical Sciences } \\ & \text { 1-7-1 Sakamoto, Nagasaki 852-8501 (Japan) } \\ & \text { E-Mail sueguchi@nagasaki-u.ac.jp }\end{aligned}$


Sadykov et al.: Peritoneal Recurrence of Initially Controlled Hepatocellular Carcinoma after Living Donor Liver Transplantation

death and one of the leading causes of death among patients with liver cirrhosis [2], screening for HCC in high-risk populations, especially liver transplantation (LT) candidates, has been recognized as a rational procedure.

Liver resection for HCC is possible only in selected cases due to the high incidence of morbidity and mortality in patients with cirrhosis and elevated portal pressure. LT for HCC has been determined to be a viable option for treatment since Mazzaferro et al. [3] reported their landmark study that presented the criteria which became known as the Milan criteria. They showed that when transplantation was restricted to patients with early HCC (radiologically defined as a single lesion $\leq 5 \mathrm{~cm}$, up to three separate lesions, none $>3 \mathrm{~cm}$, no evidence of gross vascular invasion and no regional nodal or distant metastases), a 4-year survival could be achieved for $75 \%$ of patients. These outcomes were similar to the expected survival rates for patients undergoing transplantation for cirrhosis without HCC. Later, several centers presented and analyzed their results of LT for patients with HCC in excess of the Milan criteria [4-6]. LT from cadaveric or living related donors has now become a common treatment for patients with HCC in most developed centers worldwide.

The limited availability of donor organs is a general problem in transplantation. While awaiting a donor organ, patients with HCC may be excluded from the 'waiting list' due to tumor progression. Locoregional therapy (LRT), such percutaneous ethanol injection, radiofrequency ablation (RFA), transarterial embolization (TAE), transarterial chemoembolization (TACE), stereotactic radiotherapy and radioembolization, was developed to prevent tumor progression until a suitable donor organ became available [7]. This type of therapy is often referred to as a 'bridging' treatment; however, there may also be oncological benefits of locoregional action, which indicates that these methods should be considered for use beyond the 'bridge' to transplantation in wait-listed patients. Therefore, the practice of treating HCC patients with LRT has also become a standard procedure before LT in most centers.

However, peritoneal recurrences of HCC are uncommon, especially in patients who have undergone LT. We experienced the cases of two patients with HCC peritoneal recurrence, occurring 19 and 32 months after LT, respectively, and herein describe these cases and provide a review of the literature.

\section{Case Reports}

Between August 1997 and September 2014, 74 out of 210 recipients underwent living donor LT (LDLT) at the Department of Surgery of Nagasaki University Hospital for HCC evaluated by ultrasound, multispiral computed tomography and/or gadolinium ethoxybenzyl diethylenetriamine pentaacetic acid contrasted magnetic resonance imaging (Gd-EOB-DTPA MRI). Most of the patients were accepted for LDLT within the Milan criteria.

The HCC recurrence rate in this series was $5.4 \%$, meaning that only four of the 74 patients developed a recurrence of HCC after transplantation since we strictly followed the Milan criteria. Among them, two recipients had typical types of recurrences: one patient had recurrence in the liver and another had recurrence in the lung and liver. These two patients are not presented in the current study. The cases of the other two patients with peritoneal recurrence of HCC are presented below.

Case 1

A 52-year-old male patient had been diagnosed with liver cirrhosis due to HBV infection in 1980 and had been without regular follow-up due to lack of desire on his part. In 2008, he was diagnosed with three nodules of HCC in S4 and S5, the largest being $35 \mathrm{~mm}$ in diameter 
Sadykov et al.: Peritoneal Recurrence of Initially Controlled Hepatocellular Carcinoma after Living Donor Liver Transplantation

(fig. 1a). Two months after these findings, the patient had rupture of the HCC nodule in S5 and received urgent TAE for hemostasis (fig. 1b). He underwent LDLT 3 months after the episode of ruptured HCC (fig. 2a, b), with a Child-Turcotte-Pugh (CTP) class of C (10 points), a model of end-stage liver disease (MELD) score of 10 points, and also had HCC within the Milan criteria (fig. 2c, d). The tumor marker levels before transplantation showed an increase in the PIVKA II level up to $423 \mathrm{mAU} / \mathrm{ml}$, with a normal AFP level of $7.5 \mathrm{ng} / \mathrm{dl}$. The patient was also treated following the general clinical and immunosuppressive protocol.

Peritoneal dissemination was diagnosed in this patient 32 months after LDLT (fig. 3). He started to receive adjuvant therapy with sorafenib $400 \mathrm{mg}$ without evident benefit, then after 1 month of this treatment was changed for to tegafur and uracil $400 \mathrm{mg}$, but after another 1 month this was also stopped due to lack of efficacy. After 6 months, the patient developed strong intra-abdominal pain, probably connected with the dissemination of the peritoneal tumor, and received palliative therapy. He died due to the progression of disease 70 months after transplantation. Maintenance immunosuppressive therapy was under tacrolimus with a trough level of 3-5 $\mathrm{ng} / \mu \mathrm{l}$ without any signs of rejection. This patient was the only one who had ruptured HCC before LDLT in our series.

\section{Case 2}

A 62-year-old male patient with liver cirrhosis due to HCV infection since 1993 was found to have HCC in 2003 and underwent caudate lobe resection. After surgery, he received antiviral therapy, with a sustained virological response to antiviral therapy by interferon plus ribavirin. Four months after the liver resection the patient was found to have HCC recurrence in the liver, and during the next 3 years, he consequentially received several TAE/TACE procedures for HCC in S2, S4 and S7, percutaneous ethanol injection for HCC in S7 and RFA for HCC in S2, with good clinical and roentgenological outcomes.

Thirty-eight months after the initial finding of HCC, the patient underwent LDLT from his daughter, using a left lobe graft, and his treatment followed the general clinical protocol of the center, including immunosuppressive therapy. A few days before transplantation, the patient's prognostic criteria presented with CTP class C (10 points), a MELD score of 10 points and HCC within the Milan criteria. The tumor marker levels were normal: AFP $1.9 \mathrm{ng} / \mathrm{dl}$ and PIVKA II $24 \mathrm{mAU} / \mathrm{ml}$. Histopathological study of the explanted liver showed no evidence of malignancy.

However, with elevation of AFP 19 months after LT, a single nodule of peritoneal tumor in the pelvic cavity was observed under PET/CT. Within 1 month the patient underwent peritoneal tumor resection, and histopathological investigation of the tumor revealed moderately differentiated HCC. After 3 months, the patient was accepted for adjuvant therapy with sorafenib $400 \mathrm{mg}$, but at the same time, he was observed to have recurrence of the pelvic tumor, with invasion in the rectum, and it was noted that he also had liver recurrence. TACE was performed for both the pelvis and liver tumors, and thereafter the patient was supported with palliative treatment. After about 1 month of this treatment, the patient asked to be discharged so he could go home, where he died within 3 months. Overall, the patient survived 46 months after LT. Maintenance immunosuppressive therapy was under cyclosporine with the trough level of 50-100 ng/ $\mu \mathrm{l}$ without any signs of rejection. This case was partly reported in our previous publication [8]. 
Sadykov et al.: Peritoneal Recurrence of Initially Controlled Hepatocellular Carcinoma after Living Donor Liver Transplantation

\section{Discussion}

Belghiti and Fuks [9] consider LT to be the most popular therapeutic option for HCC, because hepatectomy removes all detectable and undetectable tumor nodules and preneoplastic lesions, as well as simultaneously treating the underlying cirrhosis and preventing its distant complications. However, a major cause of death in cirrhotic patients with HCC after transplantation is tumor recurrence, which developed in 3-26\% of cases [10-12]. Avoidance of recurrence is currently not possible due to the lack of established adjuvant therapies; therefore, only adequate patient selection and preoperative management are used to ensure acceptable recurrence rates for most centers, achieving excellent survival after LT. Chemotherapy for HCC has no proven benefit $[13,14]$. On the other side, the rate of HCC recurrence after LT is lower than that after liver resection or any other type of treatment, which may be up to $80 \%$ [15-17].

Peritoneal recurrences of HCC are uncommon [18]. The risk factors after liver resection (tumor size $>50 \mathrm{~mm}$, presence of microvascular invasion, bile duct invasion, positive resection margins) were proposed in a study presented by Kow et al. [19], which included 36 patients with peritoneal recurrence of HCC among a total 1,222 cases who underwent liver resection. The authors also consider peritoneal metastases as an incurable terminal disease rarely suitable for surgical resection. Nakayama et al. [20] presented six cases observed and treated in one center without LT, and several single case reports of peritoneal recurrences of HCC in patients treated without LT have been published worldwide.

Peritoneal recurrences of HCC after LT are rare. The largest study presented in English describes only two cases of peritoneal recurrence among 685 transplanted patients, including 202 with HCC [21]. This may demonstrate another benefit of LT for HCC management compared to liver resection or treatments. Tumor dissemination due to HCC rupture could be a possible mechanism underlying the distant tumor recurrence in our second case. A few case reports have described peritoneal metastasis after ruptured HCC. Chow et al. [22] described their case of peritoneal tumor implantation after ruptured HCC, concluding that such recurrence may occur months to years after the initial presentation. Therefore, indication of LT after ruptured HCC should be carefully evaluated including staging laparoscopy. Ablative LRT techniques, including RFA and TACE, are used to promote tumor necrosis to control the progression of HCC. However, the potential impact of aggressive LRT on HCC recurrence, especially in distant sites, is still unclear and should be discussed including our previous study [8]. With regard to other possible predictors of distant recurrence of HCC, there is a consensus on the negative impact of pharmacological immunosuppression on the recurrence of HCC [23, 24]. Welker et al. [25] showed that lower levels of immunosuppressive agents are associated with a lower risk for HCC recurrence.

In conclusion, we propose that HCC peritoneal recurrence is a rare complication for patients after LT, but that it can appear, especially when a patient has any background factors that might lead to recurrence before LT, such as ruptured HCC or LRT for HCC tumors. We have experienced two such cases, both of whom underwent LT within the Milan criteria. Due to disappointing outcomes of chemotherapy for HCC, it may be necessary to establish a screening program for patients who have a ruptured HCC or have received LRT before LT.

\section{Disclosure Statement}

The authors have no conflict of interest associated with this paper. 
Sadykov et al.: Peritoneal Recurrence of Initially Controlled Hepatocellular Carcinoma after Living Donor Liver Transplantation

\section{References}

1 Fattovich G, Stroffolini T, Zagni I, et al: Hepatocellular carcinoma in cirrhosis: incidence and risk factors. Gastroenterology 2004;127(5 suppl 1):S35-S50.

-2 El-Serag HB: Epidemiology of viral hepatitis and hepatocellular carcinoma. Gastroenterology 2012;142: 1264-1273.

3 Mazzaferro V, Regalia E, Doci R, et al: Liver transplantation for the treatment of small hepatocellular carcinomas in patients with cirrhosis. N Engl J Med 1996;334:693-699.

4 Yao FY, Ferrell L, Bass NM, et al: Liver transplantation for hepatocellular carcinoma: comparison of the proposed UCSF criteria with the Milan criteria and the Pittsburgh modified TNM criteria. Liver Transpl 2002;8:765-774.

5 Shetty K, Timmins K, Brensinger MS, et al: Liver transplantation for hepatocellular carcinoma: validation of present selection criteria in predicting outcome. Liver Transpl 2004;10:911-918.

-6 Roayaie K, Feng S: Allocation policy for hepatocellular carcinoma in the MELD era: room for improvement? Liver Transpl 2007;13(11 suppl 2):S36-S43.

7 Galuppo R, McCall A, Gedaly R: The role of bridging therapy in hepatocellular carcinoma. Int J Hepatol 2013;2013:419302.

-8 Eguchi S, Hidaka M, Tomonaga T, et al: Actual therapeutic efficacy of pre-transplant treatment on hepatocellular carcinoma and its impact on survival after salvage living donor liver transplantation. J Gastroenterol 2009;44:624-629.

9 Belghiti J, Fuks D: Liver resection and transplantation in hepatocellular carcinoma. Liver Cancer 2012;1: 71-82.

10 Regalia E, Fassati LR, Valente U, et al: Pattern and management of recurrent hepatocellular carcinoma after liver transplantation. J Hepatobiliary Pancreat Surg 1998;5:29-34.

11 Grasso A, Stigliano R, Morisco F, et al: Liver transplantation and recurrent hepatocellular carcinoma: predictive value of nodule size in a retrospective and explant study. Transplantation 2006;81:1532-1541.

12 Sotiropoulos GC, Molmenti EP, Lösch C, et al: Meta-analysis of tumor recurrence after liver transplantation for hepatocellular carcinoma based on 1,198 cases. Eur J Med Res 2007;12:527-534.

13 Pokorny H, Gnant M, Rasoul-Rockenschaub S, et al: Does additional doxorubicin chemotherapy improve outcome in patients with hepatocellular carcinoma treated by liver transplantation? Am J Transplant 2005;5:788-794.

14 Söderdahl G, Bäckman L, Isoniemi H, et al: A prospective, randomized, multi-centre trial of systemic adjuvant chemotherapy versus no additional treatment in liver transplantation for hepatocellular carcinoma. Transpl Int 2006;19:288-294.

15 Lang H, Sotiropoulos GC, Brokalaki EI, et al: Survival and recurrence rates after resection for hepatocellular carcinoma in noncirrhotic livers. J Am Coll Surg 2007;205:27-36.

16 Bismuth H, Chiche L, Adam R, et al: Liver resection versus transplantation for hepatocellular carcinoma in cirrhotic patients. Ann Surg 1993;218:145-151.

17 Itamoto T, Nakahara H, Amano H, et al: Repeat hepatectomy for recurrent hepatocellular carcinoma. Surgery 2007;141:589-597.

18 Yeh CN, Chen MF: Resection of peritoneal implantation of hepatocellular carcinoma after hepatic resection: risk factors and prognostic analysis. World J Surg 2004;28:382-386.

19 Kow AWC, Kwon CHD, Song S, et al: Risk factors of peritoneal recurrence and outcome of resected peritoneal recurrence after liver resection in hepatocellular carcinoma: review of 1,222 cases of hepatectomy in a tertiary institution. Ann Surg Oncol 2012;19:2246-2255.

-20 Nakayama H, Takayama T, Makuuchi M, et al: Resection of peritoneal metastases from hepatocellular carcinoma. Hepatogastroenterology 1999;46:1049-1052.

-21 Escartin A, Sapisochin G, Bilbao, et al: Recurrence of hepatocellular carcinoma after liver transplantation. Transplant Proc 2007;39:2308-2310.

22 Chow KC, Tang CN, Lai EC, Li MK: Curative treatment for recurrent tumor implantation after ruptured hepatocellular carcinoma. Hong Kong Med J 2013;19:82-84.

23 Vivarelli M, Cucchetti A, La Barba G, et al: Liver transplantation for hepatocellular carcinoma under calcineurin inhibitors: reassessment of risk factors for tumor recurrence. Ann Surg 2008;248:857-862.

24 Chinnakotla S, Davis GL, Vasani S, et al: Impact of sirolimus on the recurrence of hepatocellular carcinoma after liver transplantation. Liver Transpl 2009;15:1834-1842.

25 Welker MW, Bechstein WO, Zeuzem S, et al: Recurrent hepatocellular carcinoma after liver transplantation an emerging clinical challenge. Transpl Int 2013;26:109-118. 


\begin{tabular}{ll|l} 
Case Reports in & \multicolumn{2}{l}{ Case Rep Gastroenterol 2015;9:29-35 } \\
\cline { 2 - 3 } Gastroenterology & DOI: 10.1159/000375117 & $\begin{array}{l}\text { @ 2015 S. Karger AG, Basel } \\
\text { www.karger.com/crg }\end{array}$ \\
\cline { 2 - 3 } & Sadykov et al.: Peritoneal Recurrence of Initially Controlled Hepatocellular Carcinoma
\end{tabular}
after Living Donor Liver Transplantation

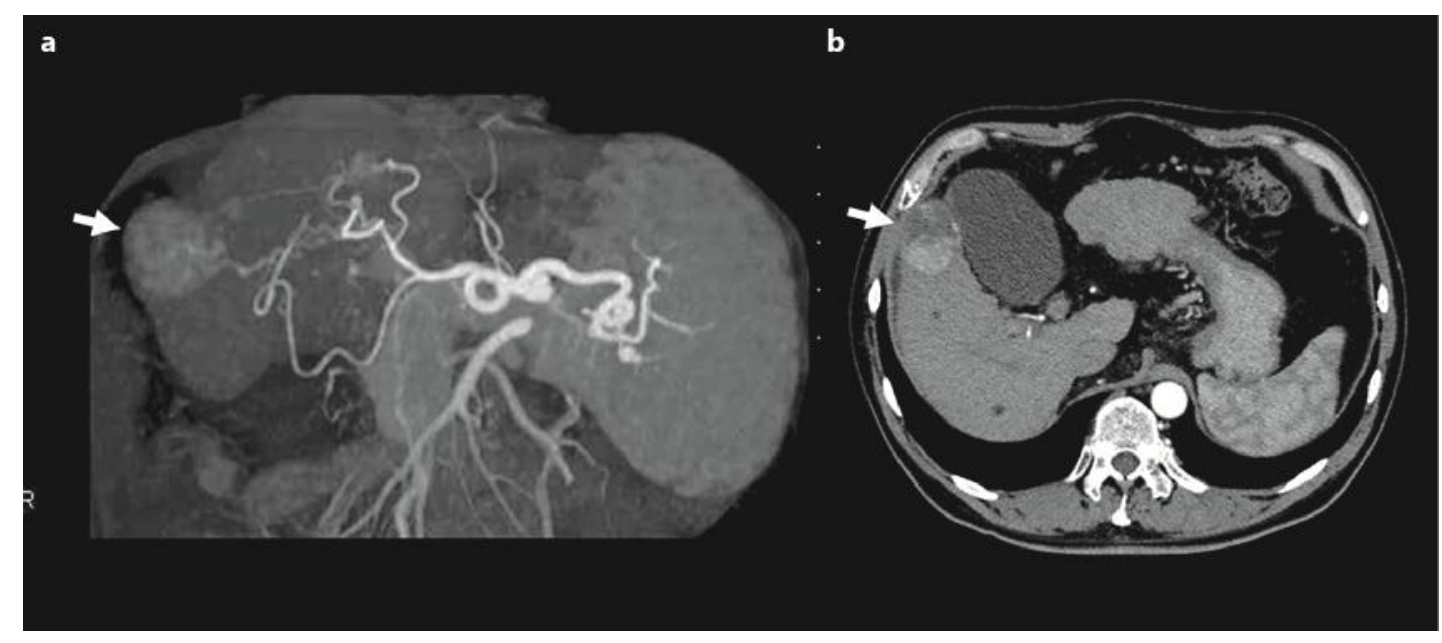

Fig. 1. A well-defined nodule $(4.0 \times 3.8 \mathrm{~cm})$ of HCC in S5 of the liver (case 1). a Before it ruptured (arrow). b After it ruptured and embolized (arrow).
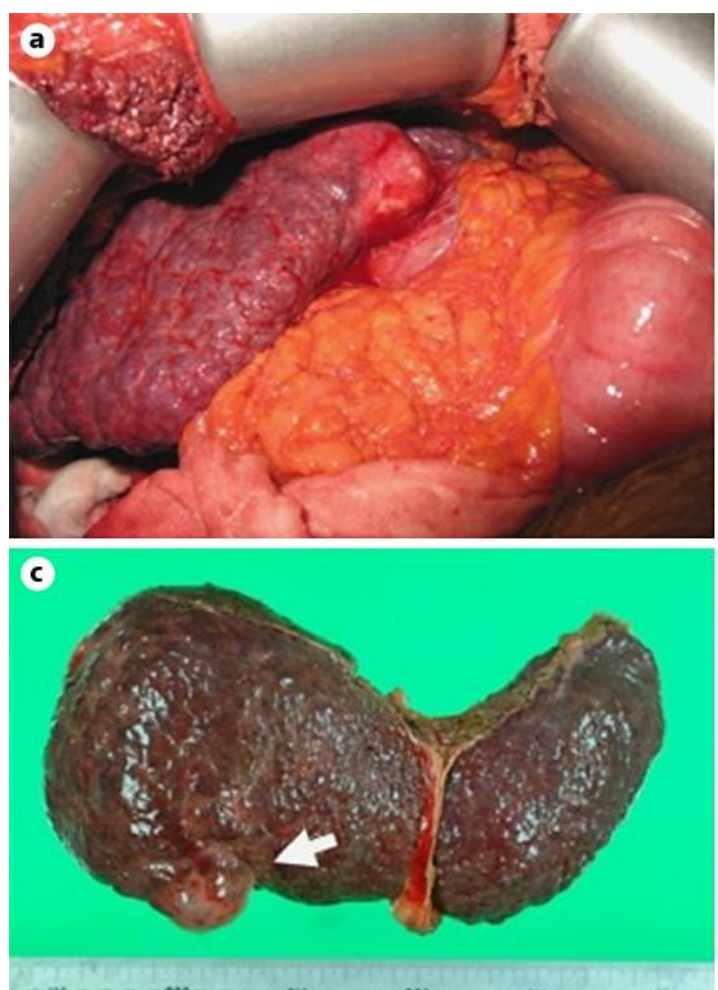

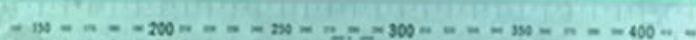
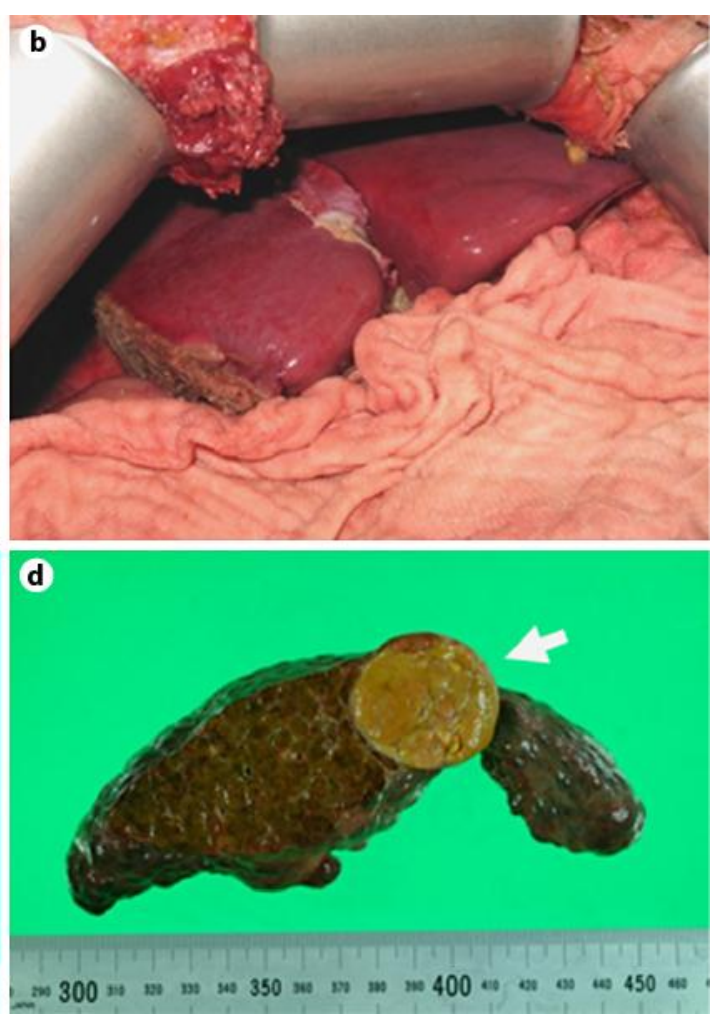

Fig. 2. a No peritoneal dissemination at laparotomy. b Left lobe graft. c Explanted liver with HCC (arrow). d Cross-section of explanted liver with HCC (arrow). 
Case Reports in
Gastroenterology

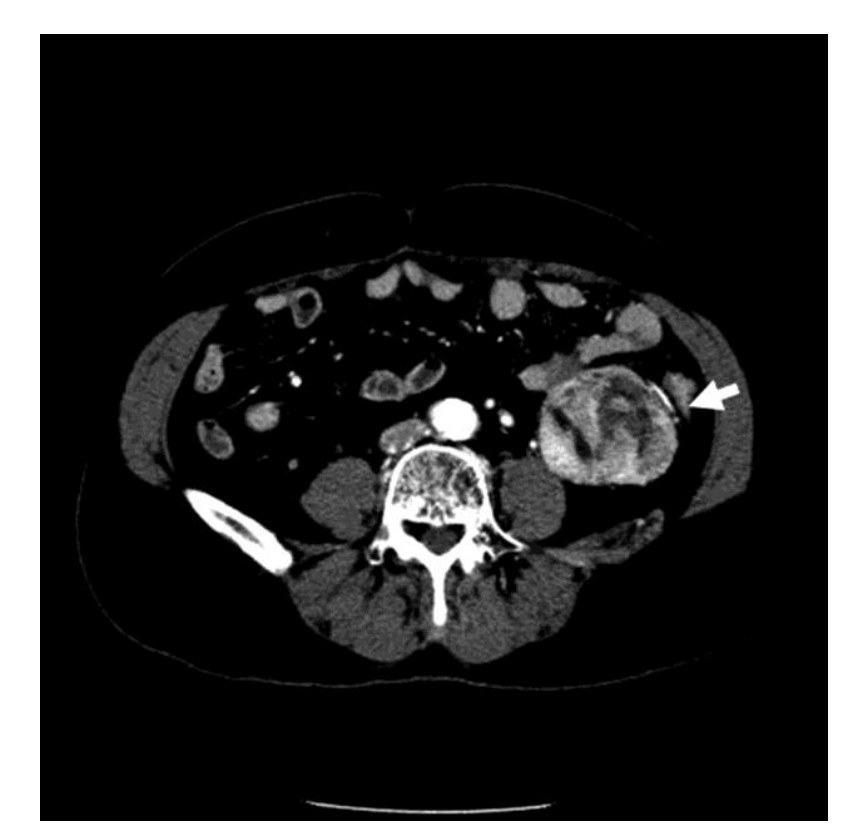

Fig. 3. The peritoneal recurrence $(5.6 \times 5.3 \mathrm{~cm})$ found by a CT scan (case 1$)$. (c) 2015 S. Karger AG, Basel www.karger.com/crg

Sadykov et al:: Peritoneal Recurrence of Initially Controlled Hepatocellular Carcinoma after Living Donor Liver Transplantation 